CHAPTER 6

\title{
The Beach of Skepticism: Kant and Hume on the Practice of Philosophy and the Proper Bounds of Skepticism \\ Karl Schafer
}

The focus of this chapter will be Kant's understanding of Hume, and its impact on Kant's critical philosophy. Contrary to the traditional reading of this relationship, which focuses on Kant's (admittedly real) dissatisfaction with Hume's account of causation, my discussion will focus on broader issues of philosophical methodology. Following a number of recent interpreters, I will argue that Kant sees Hume as raising, in a particularly forceful fashion, a 'demarcation challenge' concerning how to distinguish the legitimate use of reason in (say) natural scientific contexts from the illegitimate use of it in (say) dogmatic metaphysics. I will then go on to argue that Kant sees Hume's tendency to slide into more radical forms of skepticism as a symptom of his failure to provide a systematic or principled account of this distinction. This failure, I argue, can be traced (according to Kant) to Hume's impoverished, non-hylomorphic account of our faculties which both robs Hume of the materials necessary to construct a genuinely systematic philosophy as Kant understands this, and makes it impossible for Hume to clearly conceive of what Kant calls 'Formal Idealism.' In this way, the failings of Hume's account of causation are (for Kant) symptoms of more fundamental limitations within Hume's philosophy. I close by briefly discussing the similarities between Hume and Kant's understanding of the relationship between, first, philosophical methodology and, second, the nature of our faculties.

\section{I Hume's Influence on Kant?}

How great was the significance of Hume for Kant's critical philosophy? And was Kant's understanding of that significance true to Hume's own philosophical views and intentions? In this essay, I offer a qualified defense of positive answers to these questions. In particular, I hope to show that Hume did play a significant role in shaping how Kant conceived of the 
project of critical philosophy. And I will argue that this influence was true to very deep features of Hume's philosophy. Thus, although there are important respects in which Kant misread Hume, Kant's discussion of Hume nonetheless has the capacity to illuminate our understanding of their respective philosophical projects.

Many of these are familiar claims. For they form part of the potted history of philosophy that many of us learned as undergraduates. But among specialists on Hume and Kant, they have not fared especially well in recent years. Consider, for instance, the most familiar narrative about Kant's relationship to Hume - one that focuses on the idea of Kant as offering a response to Hume's (allegedly) skeptical or subjectivist account of causation. Plainly, Hume's views about causation played a nontrivial role in shaping Kant's thought. But as recent scholarship has stressed, Hume and Kant disagree on so many basic questions about the nature of causal relations and our cognition of them that it is difficult to see Kant's views about causation as providing us with a meaningful 'response to Hume' in any sense beyond the obvious one in which the development of an alternative to a philosophical view can be regarded as a response to it. ${ }^{\text {I }}$ Indeed, as we will see, there is a sense in which things may be even worse on this score than they seem. For it is unclear whether Kant and Hume share a common understanding of even such basic notions as 'contradiction' or 'judgment.'

In this way, among Kant scholars, it is increasingly common to encounter skepticism about reading the critical philosophy as attempting to offer a non-skeptical response to Hume's (allegedly) skeptical philosophy. But, at the same time, Hume scholars have argued that Kant's discussion of Hume is based on a natural, but pervasive, misinterpretation of some of Hume's central views. For instance, as we will discuss later, Kant's famous claim that Hume goes wrong by failing to recognize the existence of synthetic a priori truths seems to be based on a dubious interpretation of Hume's distinction between 'relations of ideas' and 'matters of fact - one which misleadingly identifies Humean 'relations of ideas' with Kantian 'analytic truths.' ${ }^{2}$ Thus, once again, there is considerable skepticism among

\footnotetext{
I See, in particular, the discussion in Watkins (2005). To be clear, I do not mean to fully endorse Watkins's verdict here. But I do think that a focus on the question of causation in particular obscures many of the most interesting aspects of Kant's relationship to Hume. For some recent attempts to draw more optimistic verdicts with respect to Kant's attempts to respond to Hume on causation, see Guyer (2008), Chignell and Pereboom (20I0), Chance (2013), Smit (2010), Landy (2015) and Qu (manuscript).

2 See Garrett (2008), Allison (2008) and Thielke (2015).
} 
Hume scholars about whether Kant's remarks about Hume are particularly revealing with respect to the relationship between Hume and Kant's actual philosophical views.

Against this background, it is only natural to wonder whether the traditional focus on the relationship between Hume and Kant is simply misplaced. This view of Kant is certainly fashionable today. For it fits perfectly with the recent fashion for reading Kant as the culmination of post-Leibnizian philosophy in Germany. ${ }^{3}$ Indeed, when viewed this way, it is tempting to regard Kant's emphasis on Hume in texts like the Prolegomena as little more than a clever piece of philosophical marketing one which misleads us about the real sources of Kant's philosophy, if it is taken too seriously.

I am sympathetic to much of this recent wave of interest in the more Leibnizian aspects of Kant's philosophy. Indeed, it seems to me uncontroversial that Kant is (in many ways) a deeply Leibnizian philosopher. But I also think it would be a mistake to see this as conflicting with a recognition of the ways in which Kant was also deeply influenced by Hume. In what follows, I hope to develop one way in which this is true. To do so, I want to turn our focus from Kant and Hume's respective views about causation - or even, more broadly, about the possibility of synthetic a priori cognition - to a set of even more basic issues concerning how Hume and Kant conceive of the practice of philosophy. It is here, I want to suggest, that Hume's most important influence on Kant lies. For it is on this very abstract level that we can best appreciate the sense in which Hume helped to awaken Kant from his 'dogmatic slumbers,' less through any particular challenge to (say) traditional views of causation, and more through Hume's basic understanding of how the very nature of human reason requires that reason engage in a sort of critical self-scrutiny. ${ }^{4}$

\subsection{The Significance of Treatise $1.4 \cdot 7$}

Before tackling larger philosophical issues, it is important to address the (long debated) question of Kant's knowledge of Hume's corpus. As has been established by the work of Kuehn and others, it is clear that by the time of the Prolegomena Kant knew many of Hume's works well - including the first

\footnotetext{
3 See Ameriks (2003), Jauernig (2008), Smit (2009), Hogan (2010) and Stang (in press).

${ }^{4}$ Here I follow in the footsteps of Kuehn (1983, 1987) and Hatfield (2001, 2003), although there are many differences between our readings. See also Thielke (2003)'s reading of Hume through the lens of Kant, which emphasizes many of the issues that I take to be important here. For related discussion of these issues, see Goldhaber (in press).
} 
Enquiry and (by 178I) the Dialogues on Natural Religion, both of which he owned in German translation. ${ }^{5}$ The Treatise, on the other hand, had not been fully translated into German at this point. But, as Kuehn has shown, Kant had access to philosophers in Konigsberg who knew the Treatise well. And, by $1770-\mathrm{I}$ at the latest, we have very good reason to believe that Kant had read an abridged translation by Hamann of section I.4.7 of the Treatise. ${ }^{6}$

This date will immediately be significant to any reader of Kant marking, as it does, the beginning of the 'silent decade' which preceded the publication of the A-edition of the first Critique. ${ }^{7}$ Thus, it is immediately tempting to think that his encounter with Hamann's translation of Treatise I.4.7 might have had a significant impact upon Kant - perhaps contributing to the crisis of faith with respect to Leibnizian metaphysics which gave rise to the critical project itself. ${ }^{8}$

If we adopt a traditional reading of the relationship between Hume and Kant, on which the key to this relationship is the status of causal judgments, we are likely to be skeptical of this possibility. After all, Treatise I.4.7 is not focused on this issue - nor does it seem likely to have changed Kant's reading of Hume's views about causation in fundamental ways. ${ }^{9}$ But this assumes a traditional picture of the nature of Hume's impact on Kant - one which focuses on causation in particular. And, once we look beyond this perspective, the hypothesis that Hamann's translation had a significant influence on Kant looks much more plausible. For Treatise I.4.7 represents Hume's most intensely skeptical moment. Indeed, as we will discuss, it is only here that we find Hume clearly expressing the idea that reason itself is naturally prone to a certain sort of self-contradiction - a view that, of

\footnotetext{
5 See Kuehn (1983, 1987). Compare Kreimendahl (1990).

${ }^{6}$ Hamann (I952, 364-70). The precise date at which Kant encountered this translation remains the subject of debate, with Ertl (2002) placing it prior to 1770 and so relevant to the themes of Kant's Inaugural Dissertation. Hamann's translation was published in two issues of the Königsbergische Zeitung in I77I under the title 'Nachtgedanken eines Zweiflers,' without any indication that it was a translation of Hume, but it seems fair to assume that Kant was aware of its source. In addition, in I772, a German translation of Beattie's Essay on the Nature and Immutability of Truth appeared, which included many quotes from the Treatise - as did Tetens's Philosophische Versuche über die menschliche Natur und ihre Entwickelung, published in 1777.

7 The importance of these years in particular is confirmed by Kant's famous letter to Herz of I772, in which Kant lays out the fundamental problem underlying the critical philosophy. That being said, the chronology here is somewhat complicated by Kant's 1783 letter to Mendelssohn, which suggests that work on what became the first Critique began as early as $1768 / 9$.

${ }^{8}$ For a defense of a stronger version of this claim than I will defend here, see Ertl (2002), a paper which deserves greater attention than it has received. As Ertl stresses, a focus on Treatise I.4.7 can unify Kant's claims about the role of antinomies and the role of Hume in inspiring the critical philosophy (compare Thielke (2003)).

9 Of course, this is not to say that issues relating to causation are absent from I.4.7.
} 
course, plays a central role in the radicalization of Kant's thought leading up to the development of the critical philosophy. ${ }^{\text {IO }}$ Thus, the idea that an encounter with Treatise I.4.7 would have transformed Kant's understanding of the depth of Hume's challenge to rationalism is hardly far-fetched.

Moreover, when we turn to the Prolegomena, it is easy to find textual evidence for the importance of Treatise I.4.7 for Kant's conception of the critical project. After all, when Kant describes the project of the Prolegomena, he not only mentions Hume by name, but also explicitly echoes one of the most famous passages of just this section of the Treatise: ${ }^{\text {II }}$

Yet these Prolegomena will bring them to understand that there exists a completely new science, of which no one had previously formed so much as the thought, of which even the bare idea was unknown, and for which nothing from all that has been provided before now could be used except the hint that Hume's doubts had been able to give; Hume also foresaw nothing of any such possible formal science, but deposited his ship on the beach (of skepticism) for safekeeping, where it could then lie and rot, whereas it is important to me to give it a pilot, who, provided with complete sea-charts and a compass, might safely navigate the ship wherever seems good to him, following sound principles of the helmsman's art drawn from a knowledge of the globe. (4:26I-2, my second emphasis)

As we will see, Kant's reference to the possibility of a 'formal science' of philosophy is especially significant here. But for the moment, I want to simply note that this passage echoes the melancholy opening paragraph to I.4.7, in which Hume writes:

Methinks I am like a man, who having struck on many shoals, and having narrowly escaped shipwreck in passing a small frith, has yet the temerity to put out to sea in the same leaky weather-beaten vessel, and even carries his ambition so far as to think of compassing the globe under these disadvantageous circumstances. My memory of past errors and perplexities, makes me diffident for the future. The wretched condition, weakness, and disorder of the faculties, I must employ in my enquiries, encrease my apprehensions. And the impossibility of amending or correcting these faculties, reduces me almost to despair, and makes me resolve to perish on the barren rock, on which I am at present, rather than venture myself upon that boundless ocean, which runs out into immensity. This sudden view of my danger strikes me with melancholy; and as it is usual for that passion, above all others, to

1o Compare Ertl (2002) and Thielke (2003).

II The metaphors at work here of course go back much further than Hume. Another particularly important point of reference for Kant in this regard was plainly Bacon's Instauratio, from which the epigraph of the second edition of the first Critique is derived. But, as Mensch (2013) points out, Kant's treatment of this metaphor is much closer to Hume's understanding of it than it is to Bacon's. 
indulge itself; I cannot forbear feeding my despair, with all those desponding reflections, which the present subject furnishes me with in such abundance. (T I.4.7.I, my emphases)

This echo provides us with further evidence that his encounter with Treatise I.4.7 had philosophical significance for Kant. As such, it also provides us with a clue about how Kant, at least at the time of the Prolegomena, understood his relationship with Hume. Namely, it suggests that, for Kant, at least some of the crucial dimensions of Hume's philosophy were well-represented by the discussion of Treatise I.4.7. Thus, it suggests that getting clearer on how Kant viewed this version of 'Hume's challenge' to philosophy is crucial to understanding how Kant viewed his relationship with Hume more generally.

\subsection{Where's the Beef? Skepticism and the Demarcation Challenge}

To consider these issues, I want to begin by asking where, at least in the Prolegomena, Kant located his primary disagreement with Hume. Here the crucial passage is the following:

The question was not, whether the concept of cause is right, useful, and, with respect to all cognition of nature, indispensable, for this Hume had never put in doubt; it was rather whether it is thought through reason a priori, and in this way has an inner truth independent of all experience, and therefore also a much more widely extended use which is not limited merely to objects of experience: regarding this Hume awaited enlightenment. The discussion was only about the origin of this concept, not about its indispensability in use; if the former were only discovered, the conditions of its use and the sphere in which it can be valid would already be given. (4:259, my emphases)

Even a superficial reading of this passage suffices to show that many of the familiar accounts of the relationship between Hume and Kant are mistaken. For example, this passage makes clear that Kant's main complaint against Hume was not that Hume failed to recognize that causal concepts were indispensable to or necessary conditions on (say) natural science or experience. Nor is it plausible that Kant's main complaint against Hume was that Hume rejected the sort of causal reasoning involved in ordinary natural science. For Kant here describes Hume as someone who 'never put in doubt' whether the 'concept of cause is right ... with respect to all cognition of nature.'

Similarly, in the second Critique, Kant compares those who read Hume as an unqualified skeptic with those who read Kant as an unqualified 
idealist $(\mathrm{CPrR}$ 5:13-I4). This is a remarkable comparison, since Kant viewed the latter reading of the A-edition of the first Critique as one of the great injustices of his life - one which both the Prolegomena and the B-edition of the Critique were meant to combat. This comparison suggests that Kant did not read Hume as a truly committed or unqualified skeptic. That is, at least in these passages, Kant does not seem to have read Hume as a 'skeptic about ordinary causal reasoning' - or, at most, he seems to have read Hume as a regretful and inconstant one.

Finally, Kant's complaint in these passages is not that Hume rejected the sort of causal reasoning involved in dogmatic metaphysics. For in this case, Kant of course agrees with Hume that such reasoning oversteps theoretical reason's proper bounds. In other words, if Hume is a 'skeptic' about such reasoning, so is Kant, at least from a theoretical point of view. ${ }^{\mathrm{I2}}$

In short, in these passages, Kant appears to think that he and Hume agree on quite a lot. For, in them, Kant reads Hume as trying to draw roughly the right line between legitimate and illegitimate forms of causal reasoning. And he takes Hume to recognize that the legitimacy of many forms of causal reasoning can be rejected only on pain of giving up natural science, something that he (rightly) thinks Hume wishes very much to avoid. ${ }^{13}$ Ultimately, he seems to credit Hume with some, albeit crude, appreciation of the basic line of argument that has come to be called a 'transcendental argument' - that is, an inference from the indispensability of a form of reasoning to its positive epistemic status.

Rather, judging by these passages, for Kant the fundamental problem with Hume's philosophy lies elsewhere - namely, that Hume lacks the resources to draw the distinction between legitimate science and illegitimate metaphysics in a principled or systematic manner. On this point, compare the following passage from the first Critique, which seems to refer to Hume (among others):

I have not avoided reason's questions by pleading the incapacity of human reason as an excuse; rather I have completely specified these questions according to principles, and after discovering the point where reason has misunderstood itself, I have resolved them to reason's full satisfaction. (Axii, my emphases)

As passages like this indicate, Kant's most fundamental complaint against Hume seems to be that Hume lacked the tools necessary to determine the

\footnotetext{
${ }^{12}$ Compare Bi9-20.

${ }^{13}$ For readings that emphasize this idea, see Kuehn (1983, 1987) and Hatfield (200I, 2003). Also compare Engstrom (1994), Watkins (2005) and Ameriks (2003).
} 
boundaries of the proper use of (say) causal concepts in the manner characteristic of what Kant calls a systematic 'formal science' of philosophy.

In this way, as Kuehn and Hatfield have stressed, Kant sees Hume as raising a demarcation challenge - a challenge Kant takes Hume to have not met, even by his own standards. ${ }^{14}$ On Kant's reading, it is precisely because Hume has not satisfactorily met this challenge that he finds it difficult to prevent his appropriate 'skepticism' about dogmatic metaphysics from sliding into an inappropriate 'skepticism' about causal reasoning in general. In other words, on Kant's interpretation, although Hume does not want to call scientific reasoning into question, he struggles to see how a principled distinction between the (hopefully) legitimate scientific use of causal concepts and the illegitimate 'more metaphysical' uses of them can be drawn.

This, in keeping with a more traditional reading of Kant and Hume's relationship, does in the end mean that Kant reads Hume as constantly sliding into a skepticism both Hume and Kant wish to avoid. ${ }^{\mathrm{IS}}$ But this is ultimately a side-effect of a more fundamental issue - and it is only insofar as this is the case that Kant reads Hume as falling into the "most rigorous skepticism with respect to the whole of natural science (as philosophy)" (CPrR 5:5I).

Given this, Kant and his contemporaries were right to see Kant as aiming more to complete Hume's project than to refute it. ${ }^{16}$ For while Kant does read Hume as consistently sliding into a radically skeptical position, he does not read Hume's project as a radically skeptical one. Rather, Kant sees Hume's slide into radical skepticism as a symptom of Hume's failure to satisfactorily and systematically complete the project of

I4 Compare:

The famous David Hume was one of those geographers of human reason, who took himself to have satisfactorily disposed of these questions by having expelled them outside the horizon of human reason, which however he could not determine(A760/B 788 , my emphasis).

Here Kant echoes the language of the first chapter of the first Enquiry, and suggests that Hume was much less successful at this geographical task than he hoped to be:

And if we can go no farther than this mental geography, or delineation of the distinct parts and powers of the mind, it is at least a satisfaction to go so far; and the more obvious this science may appear (and it is by no means obvious) the more contemptible still must the ignorance of it be esteemed, in all pretenders to learning and philosophy(EHU I.I3).

is In this way, the truth here lies between Hatfield's and Kuehn's reading and the more straightforwardly 'anti-Humean' reading endorsed by Guyer (2008), Forster (2008) and (in a modified form) Chance (2013).

16 See Kuehn (1983, 1987, 1989). 
'demarcation' that Kant associates with Hume's talk of limited or mitigated skepticism.

That Hume was concerned with this sort of 'project of demarcation' is hardly very controversial. For both the first Enquiry and the first book of the Treatise (in I.4.7) clearly wrestle with how to demarcate ordinary science from empty metaphysics. Interestingly, though, these two texts present this demarcation challenge in quite different lights. In particular, while the Enquiry suggests a rather neat and tidy 'flame-based solution' to it, Treatise I.4.7 presents it as a challenge which is extremely difficult - and perhaps impossible - to fully resolve. Most importantly, it is in I.4.7 that we find Hume's presentation of his famous 'dangerous dilemma' concerning the legitimate use of reason:

This question is very difficult, and reduces us to a very dangerous dilemma, whichever way we answer it. ... If we ... condemn all refin'd reasoning, we run into the most manifest absurdities. If we reject it in favour of these reasonings, we subvert entirely the human understanding. We have, therefore, no choice left but betwixt a false reason and none at all. ( $\mathrm{T}$ I.4.7.7, my emphases)

This is but one aspect of the more ambivalent status of reason in the Treatise as opposed to in the Enquiry - and, in particular, of the Treatise's greater emphasis on reason's tendency to undermine itself through certain sorts of natural or inevitable misuse.

On this score, the Treatise resonates far better with Kant's critical view of theoretical reason than the Enquiry. ${ }^{17}$ Of course, not having access to Treatise I.4.I, Kant could not fully appreciate the reasoning behind the 'dangerous dilemma.' But nonetheless, it is not hard to see why the discussion of this challenge in Treatise I.4.7 might have had a strong impact upon Kant. For unlike the Enquiry, which treats the demarcation challenge as more or less easy to resolve, the Treatise raises it in terms that make its solution anything but obvious. This, we can imagine, would have resonated with a Kant who, in I770-I, was wrestling with his own growing dissatisfaction with traditional, Leibnizian-Wolffian metaphysics. ${ }^{\mathrm{I}}$ In this way, we can begin to see why Treatise I.4.7 might have had an especially stimulating impact upon Kant when he encountered it. ${ }^{19}$ In this way, it is

${ }^{17}$ In particular, as Ertl (2002) and Thielke (2003) discuss at length, this aspect of Hume's views clearly anticipates Kant's own critical views about reason's propensity to generate antinomies.

${ }^{18}$ Of course, as the Dissertation makes clear, this dissatisfaction emerges in stages. Unfortunately, there is no space here to discuss the Dissertation.

I9 This challenge is not as prominent in other parts of the Treatise as it is in the corresponding parts of the Enquiry. See Qu (manuscript). But the parts of the Treatise Kant had access to did not support such a distinction between the texts. 
not so surprising that it seems to have been Treatise I.4.7, and not the first Enquiry, which was the immediate spur to Kant's 'awakening from dogmatism.'

\subsection{The Grounds of Hume's Failure}

So, why, according to Kant, does Hume fail to provide a satisfactory response to this demarcation challenge? The text of the Prolegomena provides at least three important clues to this question. First, there is Kant's insistence that the real issue between him and Hume relates to the "origin of this [causal] concept" and that "if the former were only discovered, the conditions of its use and the sphere in which it can be valid would already be given" (4:259). Second, there is Kant's charge that Hume fails to accomplish his aims because he does not recognize the existence of synthetic a priori cognition. And third, there is Kant's repeated insistence that Hume's account of causal concepts forces him to regard causal "necessities" as "nothing but a long-standing habit of finding something to be true and consequently of taking subjective necessity to be objective" (4:277).

Each of these is obviously relevant to Kant's dissatisfaction with Hume. But none of them, I think, gets to the bottom of it. For example, Kant does complain that Hume misidentifies the source of causal concepts:

Our skeptic ... made a principle of affinity, which has its seat in the understanding and asserts necessary connection, into a rule of association, which is found merely in the imitative imagination and which can present only contingent combinations, not objective ones at all. (A766/B794)

But this cannot be the real heart of the matter here, since there are other philosophers, such as Tetens, who do locate the source of these concepts in the understanding, but nonetheless, according to Kant, fail for reasons that are quite similar to Hume. ${ }^{20}$ So, to discover the real ground of Hume's failure, we have to dig deeper.

Similarly, for all its obvious importance, a focus on the possibility of synthetic a priori cognition as the primary locus of disagreement between Kant and Hume can easily obscure the real issues at stake between them. For, it is far from clear that Hume actually does neglect the category of synthetic a priori cognition when this category is understood in Kant's terms. In particular, while Hume does partition cognition into 'relations of

${ }^{20}$ Compare the discussion in Dyck (20II). 
ideas' and 'matters of fact,' it is misleading to follow Kant in thinking of this as involving a distinction between judgments that are (on the one hand) analytic and a priori and ones that (on the other hand) are synthetic and a posteriori.

While 'relations of ideas' are a priori in Kant's sense, they are not analytic in anything like his sense of these terms. For while both Humean 'relations of ideas' and Kantian 'analytic truths' are defined in opposition to some notion of 'contradiction,' this commonality between 'relations of ideas' and 'analytic truths' is ultimately misleading. In particular, Hume's understanding of 'contradiction' is very different from Kant's. While Kant conceives of contradictions in broadly formal terms, for Hume 'contradiction' is a substantive notion relating to the 'unthinkability' of something whether or not that 'unthinkability' is grounded in any formal or logical contradiction. In this way, Hume's notion of 'contradiction' includes within its scope forms of 'unthinkability' that Kant would view as grounded in synthetic a priori principles. ${ }^{2 \mathrm{I}}$

Thus, the class of Humean 'relations of ideas' is a different and (in many ways) broader category than the class of Kantian 'analytic judgments.' Indeed, there is a sense in which it would have been more accurate for Kant to describe Hume as neglecting the category of analytic a priori judgments. For Hume's nonformal account of "relations of ideas" is in many ways closer to Kant's conception of synthetic a priori judgment than it is to Kant's conception of analytic judgment.

As a result, while the status of the synthetic a priori is plainly central to Kant's relationship with Hume, in order to clearly understand why and how this is the case, we need to dig deeper. Fortunately, this issue points us in just the right direction. For Hume's nonformal account of the nature of 'relations of ideas' is closely connected with Kant's fundamental source of dissatisfaction with Hume's response to the demarcation challenge namely, that Hume lacks a philosophically satisfactory account of our mental faculties. It is to this that I want to turn - leaving to the side, for the moment, our third 'clue' and the familiar charge that Hume's account of causation secures only a 'subjective necessity' for our causal concepts.

\subsection{Hume's Systematic Failure and Formal Idealism}

Why, then, according to Kant, does Hume's account of our faculties prevent him from developing a genuinely systematic answer to the

${ }^{21}$ Compare Garrett (2008), Allison (2008), Thielke (2015). 
demarcation challenge? Here the crucial point is the following. For the critical Kant, human understanding bottoms out in a set of basic faculties faculties that cannot be explained in more fundamental terms - but which nonetheless provide a non-arbitrary basis for further explanations:

But all human insight is at an end as soon as we have arrived at basic powers or basic faculties; for there is nothing through which their possibility can be conceived, and yet it may not be invented and assumed at one's discretion. (CPrR 5:46-7, my emphasis)

In this sense, during the critical period, Kant is what we might call a sort of capacities- or faculties-first philosopher. ${ }^{22}$ But, at the same time, the critical Kant also believes that philosophy can form a rationally satisfactory system only if it involves a network of cognitions which is based on a priori principles/ideas:

Philosophy in sensu scholastico involves two things, (I.) A sufficient supply of cognitions of reason. (2.) A correct connection of these, or a system. For a system is the connection of many cognitions in accordance with an idea. (Kant (1992C), 16:799)

Taking these points together, there is little question for Kant about where philosophy is to find these unifying principles/ideas. For Kant, these principles must be located by looking to the very faculties that he takes to be explanatorily fundamental (at least from our point of view). Thus, it is crucial, for Kant, to the viability of philosophy as a genuinely systematic science that our basic rational capacities be capable of providing us with principles of just this sort. In short, as the critical Kant sees things, a set of foundational, and nonarbitrary, principles for philosophy can only be provided by our basic rational faculties and the principles at work in them: ${ }^{23}$

In this way the a priori principles of two faculties of the mind, the faculty of cognition and that of desire, would be found and determined as to the conditions, extent, and boundaries of their use, and a firm basis would thereby be laid for a scientific system of philosophy, both theoretical and practical. (CPrR 5:I2, my emphasis)

22 The focus on capacities is common to many early modern philosophers. Indeed, as we will see, there is a sense in which Hume too might be thought of in this way. See Schafer (2019b, manuscript) for more discussion.

${ }^{23}$ Here I move quickly over complicated questions about the different senses in which Kant speaks of 'principles' (Prizipien or Grundsätze) in a philosophical context. 
So, for Kant, philosophy can be systematic only insofar as it is grounded in a unified system of nonarbitrary principles. And these principles can only be provided by the basic faculties of the mind. But all this, for Kant, is only possible insofar as one accepts a broadly hylomorphic account of the nature of our faculties on which these faculties are individuated in terms of the form or principle that structures their activities and representations. As a result, for Kant, a hylomorphic account of our faculties is ultimately what makes genuinely systematic philosophy possible. ${ }^{24}$

Given this, we can see that Kant rejects Hume's account of the origins of the concept of cause not simply because this account mis-locates the origin in the wrong faculty. Rather, his main complaint is that Hume's conception of our faculties in general is too impoverished to do the work required by systematic philosophy. In other words, according to Kant, if our faculties were as Hume imagines them to be, genuinely systematic philosophy would be impossible, no matter which faculty we traced the concept of cause to.

In this way, for Kant, Hume's failure to accept a hylomorphic conception of our faculties reduces him to a 'universal empiricism of principles' which is ultimately a philosophy without genuine principles at all (CPrR 5:I3-I4, 5:52-3). ${ }^{25}$ This, of course, is closely connected with the possibility of synthetic a priori cognition for Kant (A764-5/B792-3). For synthetic a priori cognition is, for Kant, only possible because of the existence of a priori forms of synthesis associated with each of our basic cognitive faculties. Indeed, the connection between Hume's failure to develop a genuinely systematic form of philosophy and his failure to properly account for the possibility of synthetic a priori is even tighter than this since the principles that make systematic philosophy possible are the most fundamental instances of synthetic a priori human cognition, for Kant. Thus, for Kant, Hume's failure to develop an adequate account of synthetic a priori cognition is similarly rooted in his nonformal or nonhylomorphic conception of our faculties. ${ }^{26}$

${ }^{24}$ For example, the moral law both is the fundamental principle of pure practical reason and the foundation for systematic moral philosophy. (To be clear, this is meant as a necessary, but not sufficient, condition on the possibility of systematic philosophy. For example, systematic philosophy for Kant will be possible only insofar as these capacities themselves form a systematic unity.)

${ }_{25}$ This is related to Kant's charge that Hume engages only in the "censorship" and not the "critique" of reason: "not the censorship but the critique of pure reason, whereby not merely limits but rather determinate boundaries of it ... are not merely suspected but are proved from principles." (A760-I/ B788-9)

${ }^{26}$ Of course, Hume himself was quite suspicious about the significance of many Aristotelian concepts (see T I.4.3 in particular). One important question is whether Hume would find Kant's attempts to 
Of course, the a priori forms of synthesis associated with Kant's hylomorphic conception of our faculties can (according to Kant) only be a source of synthetic a priori cognition of objects if we conceive of these objects as having the form they do in virtue of the form of our faculties that is, as being appearances as opposed to things in themselves. So, this second issue - of how Kant's conception of our faculties provides him with an account of synthetic a priori cognition - is closely connected with the third issue we noted earlier - namely, Kant's complaint that Hume's theory cannot secure the 'objectivity' of our causal concepts. ${ }^{27}$ For it is plain that Kant sees this as a product of Hume's failure to recognize the power of the Copernican Turn at the heart of Transcendental Idealism. And this 'turn,' of course, rests on the idea that the formal features of the objects of cognition might be grounded in formal features of our cognitive faculties. $^{28}$

As this indicates, Kant's understanding of the Copernican Turn itself rests on the distinction we have been discussing between the 'form' of a faculty and the 'matter' this form operates on. After all, once again, on this view it is precisely the form of objects that holds in virtue of the form of our faculties. Thus, the very idea of Transcendental Idealism must (for Kant) be paired with a distinction between the form and the matter of both our representations of objects and these very objects themselves. In other words, it is only in this doubly hylomorphic context that we can clearly recognize the possibility of the distinctive sort of idealism Kant endorses. For precisely this reason Kant often finds the label 'formal idealism' more apt than the more familiar label of 'Transcendental Idealism.' ${ }^{29}$

Formal idealism in this sense involves a package of views, the core of which are the following:

make non-mysterious use of these notions at all plausible. Unfortunately, there is no space here to discuss this issue in detail. But we can note that Kant at least attempts to provide an account on which some uses of the form-matter distinction do not involve an appeal to mysterious 'occult qualities' of the sort Hume objected to. Indeed, one potential attraction of a more hylomorphic conception of, say, the relationship between sensibility and the intellect is that it may not give rise to the sort of metaphysical gap between the two that Hume and Kant both associated with Cartesian dualism.

27 See, e.g., A95/B127, CPrR 5:51.

${ }^{28}$ This is especially clear in 4:313's presentation of the essence of Kant's "complete solution of the Humean problem.” For discussion of transcendental idealism, see Stang (2016a) and Boyle (manuscript).

29 As Colin McLear has pointed out to me, it seems plausible that an exchange with Lambert in the late I76os played a crucial role in Kant's recognition of the significance of hylomorphism for his philosophical project (see Io:64). Plausibly, it was this exchange that in part explained the sudden prominence of hylomorphic notions in the Dissertation. 
(I) A hylomorphic conception of our cognitive faculties.

(2) A hylomorphic conception of the objects of cognition.

(3) A metaphysical claim about the relations of dependence that obtain between our cognitions and their objects (qua appearances) on which the form of appearances depends on the form of our cognitive faculties.

Of course, Kantians have often downplayed the centrality of Transcendental Idealism for Kant's thought in general, and his relationship with Hume in particular. But with respect to Kant's dispute with Hume at least, this strategy seems to me unpromising. After all, in giving his 'complete solution of the Humean problem' in the Prolegomena, Kant stresses again and again the role of Transcendental Idealism in making this solution possible. For example, he writes:

This complete solution of the Humean problem ... thus restores to the pure concepts of the understanding their a priori origin, and to the universal laws of nature their validity as laws of the understanding, but in such a way that it restricts their use to experience only, because their possibility is founded solely in the relation of the understanding to experience: not, however, in such a way that they are derived from experience, but that experience is derived from them, a completely reversed type of connection that never occurred to Hume. (4:313, my emphasis) ${ }^{30}$

Obviously, there is much more to be said about each of these issues. But I hope this indicates that Kant's various complaints against Hume are, in fact, more closely connected than they might seem. For at the root of all these complaints (for Kant), lies Hume's failure to develop an adequate hylomorphic account of our basic rational capacities. As I have just argued, it is the failure that (again for Kant) explains why Hume does not capture the true source of a priori concepts. And it is this failure that makes it impossible for Hume to develop an adequate account of the synthetic a priori cognition - at least in part because it makes it impossible for Hume to clearly recognize the power of what Kant calls 'formal idealism.' ${ }^{31}$

${ }^{30}$ Contrary to the manner in which Kant's dispute with Hume is often presented, what is at issue in passages like this is not primarily a question of 'justification.' That is, the primary question at stake here is not the grounds or reasons I have for making causal judgments. Rather, it is the more fundamental question of how these concepts can achieve the relation to objects that is required if they are to become genuine cognitions in Kant's sense of this term. For recent discussion of Kant's view of cognition, see Smit (2000, 2009), Tolley (2017), Watkins and Willaschek (2017) and Schafer (2019c, in press).

${ }^{31}$ Of course, there is much more to be said about these questions - e.g., we might wonder why this sort of 'formal idealism' is preferable to the sort of idealism that we find in (say) Berkeley. 
Furthermore, it is this failure that (for Kant) makes it impossible for Hume to develop philosophy as a 'formal science' - and so, to provide us with a systematic response to our demarcation challenge. In all these ways, Kant's complaints about Hume are ultimately rooted in Hume's impoverished, nonformal account of our faculties. ${ }^{32}$ Thus, if we want to give a unified reading of Kant's dissatisfaction with Hume on these points, we should focus here.

\subsection{The Accuracy of Kant's Reading of Hume}

But, if this is right, is Kant accurate in his reading of Hume? To consider this, let us begin by comparing Hume and Kant's respective accounts of the nature of our mental faculties. As already noted, there is an important sense in which Kant actually underestimated the depth of his differences with Hume on this score.

To see why, consider again our faculties for reasoning. Hume, following Descartes and Locke, generally conceives of the nature of reasoning in 'informal' terms. That is, Hume thinks of reasoning as involving a chain of connected intuitions, whose nature cannot be captured in terms of their 'logical form. ${ }^{33}$ As we have discussed, this picture of inference is very different from the one we find in Kant. In particular, one of the respects in which Kant remains a Leibnizian throughout his career is his allegiance to an Aristotelian account of the nature of inference, on which inferences can be described in terms of the logic form of the judgments they involve. So, even though Kant does confuse Hume's notion of 'relations of ideas' with his conception of 'analytic truths,' he is correct with respect to the larger issue here. There is a significant gap between Hume's 'informal' or non-hylomorphic conception of our faculties and Kant's hylomorphic conception of the same. ${ }^{34}$

For these reasons, we get a better grip on what Kant gets right about Hume if we focus, not on synthetic cognition, but rather on the broader

32 This is one reason why the issue of whether we locate the source of these concepts in the understanding or in sensibility is something of a red herring.

33 See Owen (1999). That being said, there is a place where Hume does introduce certain 'formal elements' into his account of human cognition - namely, via his account of the manner in which human thought is structured by the formal or syntactic features of public language. For more on this, see Schafer (2019a).

34 This is one reason why, say, Waxman (2008)'s focus on a priori forms of sensible intuition as the main difference between Hume and Kant is too narrow. The fundamental issue that separates Hume and Kant in this area is one that arises for any of our mental faculties, and not merely for sensibility in particular. 
question of Hume's nonformal account of our mental faculties. In particular, a focus on the synthetic a priori invites an easy Humean response namely, that Kant simply misunderstands Hume on this point. But if we focus on the broader issues, we can see that Kant is not missing the truly fundamental issues at stake between him and Hume.

Let us turn, then, to our second main bone of potential contention between Hume and Kant: the issue of formal or transcendental idealism. Here the crucial question is whether Kant is right to see Hume as failing to put together our representations and their objects in the manner the formal idealist does. There are readings of Hume that see him as a sort of protoTranscendental Idealist. ${ }^{35}$ But whether or not such a reading is ultimately defensible, it is easy to see why Kant did not read Hume in this way. For example, consider the following passage from Treatise I.4.7:

Nothing is more curiously enquir' $\mathrm{d}$ after by the mind of man, than the causes of every phaenomenon; ... And how must we be disappointed, when we learn, that this connexion, tie, or energy lies merely in ourselves, and is nothing but that determination of the mind, which is acquir'd by custom, and causes us to make a transition from an object to its usual attendant, and from the impression of one to the lively idea of the other? Such a discovery not only cuts off all hope of ever attaining satisfaction, but even prevents our very wishes; since it appears, that when we say we desire to know the ultimate and operating principle, as something, which resides in the external object, we either contradict ourselves, or talk without a meaning. ( $\mathrm{T}$ I.4.7.5, my emphases)

In such passages, Hume seems to be saying explicitly that we cannot form any meaningful conception of necessary connections insofar as we attempt to think of these connections as 'residing in external objects.' Rather we must instead view them lying 'merely in ourselves' and as being 'nothing but that determination of the mind.'

Whether or not he was right to do so, it is hard to imagine that Kant would have read such passages as anything but an endorsement of a merely subjective view of 'necessary connections. ${ }^{36}$ Again, for Kant, this endorsement is the product of a false dichotomy that Transcendental Idealism allows us to overcome - namely, a dichotomy between locating the 'necessity' of causal connections 'in the objects' and locating them 'in our mind.' For the point of Transcendental Idealism is to provide us

\footnotetext{
35 See Waxman (2008), Ainslie (2015).

${ }^{36}$ Indeed, the language Kant sometimes uses to make this point against Hume sometimes seems to echo just this passage.
} 
with a way of conceiving of the objects of cognition on which we need not choose between locating necessary connections in the objects or in our faculties. Rather, for the Transcendental Idealist, the objects themselves have an essential relation to our faculties of cognition. And, as a result, we can regard this necessity as lying in the objects (qua appearances) precisely because these objects (qua appearances) have the form they do in virtue of the fact that our cognitive faculties have a corresponding form.

To be clear, there are other texts of Hume's that complicate this interpretation of his views. ${ }^{37}$ But many of these texts were not available to Kant, at least to our knowledge. So whatever interpretation of Hume's relationship to Transcendental Idealism we ultimately prefer, it is easy to understand why Kant did not read Hume as a Transcendental Idealist. ${ }^{38}$

\subsection{Principles of Demarcation: Formal Idealism and the Title Principle}

For the most part, Kant's reading of Hume has dominated our discussion quite reasonably given our topic. But before concluding, I want to give Hume a chance to speak for a moment. If the reading discussed here is correct, Kant's deepest concern about Hume's philosophy is that Hume's nonformal account of our faculties makes it impossible for Hume to give a principled and systematic response to the demarcation challenge we laid out at the beginning of this chapter. We have said a good deal about what Kant takes a successful response to this challenge to require. But we have said very little about Hume's response to it.

As I have already indicated, in the Treatise, the climax of Hume's anxiety about this challenge (and related issues) comes with the famous 'dangerous dilemma' toward the middle of I.4.7. In his discussion of these issues in the Treatise, Hume's immediate response to this dilemma seems to take the form of what Garrett has dubbed the 'Title Principle':

Nay if we are philosophers, it ought only to be upon sceptical principles, and from an inclination, which we feel to the employing ourselves after that manner. Where reason is lively, and mixes itself with some propensity, it ought to be assented to. Where it does not, it never can have any title to operate upon us. $(\mathrm{T} \text { I.4.7.1I })^{39}$

${ }^{37}$ For example, see T I.3.I4.28.

${ }^{38}$ For more discussion, see Allison (2008), Garrett (2008) and Schafer (2009).

39 Hamann's translation of this passage renders 'ought' as 'müssen,' thereby making the normative thrust of this passage less clear. On the other hand, Hamann translates 'any title' as 'ein Recht,' which does have a clearly normative connotation (Hamann (1952), 369). 
Once again, it is not hard to see the Title Principle's focus on the question of when reason has any 'title' to operate upon us might have resonated with Kant's emerging interest in the questions of quid juris which come to the fore in the critical philosophy. But here I want to focus on how the Title Principle might serve as a response to the demarcation challenge that we have been discussing.

There is an extensive recent literature on the Title Principle. ${ }^{40}$ But this literature has tended to focus on the question of the role of this principle within Hume's positive or anti-skeptical epistemology. I think this is a perfectly legitimate way to view this passage. But seeing this debate through Kant's eyes should help us to see it in a different (although not incompatible) light - namely, as a contribution to a project of distinguishing legitimate (scientific) forms of reasoning from illegitimate (often metaphysical) forms thereof.

This is connected with the project of developing a non-skeptical epistemological account. But it is, at least in the first instance, probably best viewed as a project within regulative epistemology. For the immediate question here is how we ought to reason or form beliefs (insofar as this is subject to our direct or indirect control) - and not, say, what is the proper account of knowledge or justification or the like. These questions may well be connected, but one might also take the proper regulation of belief to have rather less to do with, say, justification or knowledge than one might have expected to be the case.

Given this, in Hume and Kant, we have (at least) two candidate responses to the demarcation challenge. ${ }^{4 \mathrm{I}}$ So I want to close by considering how these responses might compare - both from Kant's and from Hume's point of view. From what we have already said, I think it is fairly obvious why Kant would be unsatisfied with the Title Principle. In particular, he would claim that Hume's response is unprincipled and unsystematic, and lacking the connections with both the nature of our basic cognitive faculties and the nature of the objects of cognition that a genuinely systematic account requires.

But what would Hume say about this comparison? There is a certain sense in which Hume would, I think, agree that his response to this challenge is less systematic than Kant's. For however we understand the Title Principle, in its sensitivity to our inclinations and propensities, it does

\footnotetext{
${ }^{40}$ For an excellent overview of these debates, see Garrett (20I5). For my distinctive take on them, see Schafer (20I4, 20I9a).

${ }^{41}$ At least two because the first Enquiry may offer a further response to this challenge which is different from the Treatise's.
} 
seem to give a 'less principled' response to our challenge than Kant's neat distinction between, first, cognitions of appearances and, second, mere thoughts of things in themselves. Indeed, insofar as there is a 'system' behind Hume's claims here, it seems likely to be something more like the 'system' we find in his ethics - one that is built less on 'basic rational principles' and more on certain 'sense-like' responses, once these have been appropriately 'corrected.' ${ }^{42}$

Indeed, the Title Principle - and Hume's views about the normative significance of reason more generally - in some sense represents the inverse of Kant's views. Kant ultimately locates the source of error or irrationality in what he calls "the unnoticed influence of sensibility" upon our higher rational faculties (A294/B350-I). Thus, for Kant, so long as reason is operating solely in accordance with its own internal principles, it will never be the source of any error or irrationality. So, for Kant, the normative authority of reason is ultimately always an authority over sensibility or, better, over our use of our faculties insofar as this use is subject to the potential 'hindrances' or 'unnoticed influences' of sensibility.

For Hume, the situation here is precisely the opposite. As the Title Principle makes clear, the faculty of reason does not possess any sort of intrinsic normative authority for Hume. Rather, on Hume's view of things, it is only insofar as this faculty 'mixes' with the 'propensities' of our more sensible faculties that it gains any sort of authority over us. Thus, where Kant views sensibility primarily as introducing the possibility of error and irrationality into the use of a faculty of reason that, on its own, would be free from such problems, Hume seems to view our sensible faculties (once properly corrected) as determining when and how reason 'ought to be assented to.' ${ }^{43}$ In this way, Hume and Kant have fundamentally opposed pictures of the ultimate 'sources of normativity' and their relationship to our sensible faculties.

So, does this mean that Kant's complaints against Hume on this score are question-begging - for example, that Kant simply presupposes a demand that philosophy be 'systematic' which Hume would reject? There is something to this thought, but I do not think Kant's complaints against Hume can be dismissed as easily as this. For one, Hume himself, at least in the Treatise, hardly seems to be completely satisfied with his

42 This claim rests on my own reading of these passages. But the basic point would, I think, apply on many readings of Hume. For more discussion, see Schafer (2014, 20I9a).

${ }^{43}$ For more on Hume's views about the normative authority of reason, see Schafer (2015). 
response to these concerns. ${ }^{44}$ And the same can be said for most of Hume's readers, including many of the most sympathetic. So, it is not as if the issues that Kant is raising here are completely foreign to Hume's philosophy. For Hume himself seems to share at least some of Kant's concerns about whether the Title Principle really represents a satisfying response to the 'dangerous dilemma. ${ }^{\text {'5 }}$

With this in mind, I want to close by returning to our early discussion of the differences between Kant's and Hume's conceptions of our faculties. As we discussed previously, for Kant every faculty is associated with a form that governs its activity - and this form can be translated into a principle which provides a foundation for the associated area of philosophy. Thus, for example, the moral law both is the fundamental principle of pure practical reason and provides a foundation for systematic moral philosophy.

Hume, on the other hand, generally conceives of our faculties using an (admittedly complicated) analogy with the 'senses. ${ }^{46}$ So, instead of conceiving of the moral faculty in terms of certain formally specifiable principles, Hume conceives of it as generating a distinctive species of impression of reflection - which then may be 'corrected' so as to arrive at inter-subjectively shared moral categories. ${ }^{47}$

As we have already seen, this difference influences many other aspects of Hume's and Kant's philosophies. But, interestingly, the central importance of this question is due to something that Hume and Kant do agree upon. In particular, despite their many differences, Hume and Kant share a common conception of how the nature of our faculties should inform the proper foundations of philosophy. For both, in their own way, agree that philosophy must come to an end with certain facts about the nature of our basic cognitive faculties. ${ }^{48}$ Thus, as we have seen, the differences in how Hume and Kant understand our faculties translate into a difference in how

${ }^{44}$ Again, in the Enquiry, Hume at least presents himself as much more satisfied with his account there of these matters. This represents a sense in which the Treatise's presentation of these issues might have resonated more deeply with Kant.

45 Of course, as Harris (2015) discusses at length, Hume's relationship to 'systematic philosophy' shifts during his life. In particular, while the Treatise is meant to represent a contribution to philosophy in this (rather academic) sense, Hume's understanding of his own work evolves to emphasize a different, and less explicitly systematic conception of the sort of intellectual activity he is engaged in.

${ }^{46}$ Compare Garrett (2015)

47 Again, it is at this second level, where we encounter the sort of 'correction' required for the development of shared linguistic conventions, that we encounter formal features of the sort that Kant tends to focus on.

$4^{8}$ This is, if anything, clearer in the Enquiry with its focus on "mental geography" (EHU I.I2). 
they conceive of the proper foundations of philosophy itself. For Kant, philosophy must come to an end with a set of basic principles, which characterize our faculties in the most basic terms available to us. For Hume, on the other hand, philosophy comes to an end with the sensible responses of the various 'senses' or 'propensities for feeling' we possess. Thus, it is ultimately Hume's 'informal' conception of our faculties that explains why he meets the demarcation challenge in the "unprincipled" manner of the Title Principle. 